\title{
ANALISIS DAN IMPLEMENTASI MIKROTIK ROUTER BOARD RB450G UNTUK MANAJEMEN JARINGAN (STUDI KASUS : BADAN PENGKAJIAN DAN PENERAPAN TEKNOLOGI SUB BALAI BESAR TEKNOLOGI ENERGI (B2TE-BPPT) SERPONG)
}

\author{
Rahmat Rizkiyanto \\ Lembaga Penerbangan dan Antariksa Nasional
}

\begin{abstract}
The importance of a management of the network in B2TE and optimize use of existing network devices. During this time, the network system that is running can't be managed properly. There are still problems, especially related to topology, traffic network system, bandwidth, access rights, and the login process. On the basis of these, carried out an analysis and implementation of development using Network Development Live Cycle (NDLC) with activity analysis, design, prototype simulation, implementation, monitoring, and management. Development method is applied to solve problems that occur. Data collection methods used are the methods of observation and interviews with the B2TE and do a similar study. To resolve issues related to topology, topology implemented using the router board. For traffic network system, load balancing system implemented by the method of Per Connection Classifier (PCC). Queue tree with Hierarcial Token Bucket (HTB) method and Per Connection Queue (PCQ) and hotspot system is applied to solve problems related to bandwidth and permissions. Single sign-on system (SSO) with Open LDAP and RADIUS functioned to minimize the use of username and password during the login process. From the test results of the implemented system, the selection router board it is appropriate to handle the problem topology. Load balancing with the PCC method, queue tree with HTB and PCQ methods and systems hotspot capable of answering traffic problems on the issue of network systems, bandwidth, and permissions. While the system SSO is capable of handling problems login process. For further development, it is expected that the system has been running for bandwidth management rule can be added to separate the local and international bandwidth. Then, for security, made the policy in terms of access to the IP address and port. In terms of permissions, can be applied to the scheduling of access to certain sites. For the development of SSO, can be applied SSO system that can access multiple applications.
\end{abstract}

Keyword : Load Balancing, Bandwidth, PCC, HTB, PCQ, Open LDAP, RADIUS, NDLC, SSO.

\section{PENDAHULUAN}

Perkembangan pertukaran informasi dimana sangat banyak pemakai teknologi yang menggunakan layanan dan data yang sama dengan tingkat akses yang berbeda. Sama halnya pada teknologi internet yang terus bergerak maju seiring dengan perkembangan teknologi. Jaringan internet saat ini merupakan satu hal yang penting dalam sebuah perusahaan atau instansi. Dengan adanya jaringan internet, kegiatan komunikasi yang dilakukan menjadi lebih mudah, efektif, dan hemat waktu serta berbagai manfaat lainnya. Ketika suatu jaringan sudah dibuat dan diaplikasikan, selanjutnya perlu diperlukan suatu manajemen dan optimasi agar jaringan yang sudah diaplikasikan memiliki kinerja yang semakin baik dan maksimal (Fatimah Indraswati, 2011).

Badan Pengkajian dan Penerapan Teknologi SUB Balai Besar Teknologi dan Energi (B2TE-BPPT) merupakan salah satu pusat keunggulan pengembangan teknologi energi, diharapkan mampu berperan untuk mendorong pertumbuhan industri energi serta 
ANALISIS DAN IMPLEMENTASI MIKROTIK ROUTER BOARD ...

penerapan teknologi yang efisien, handal dan ramah lingkungan bagi pemecahan permasalahan nasional. Oleh karena itu, instansi ini sangat perlu didukung oleh performa teknologi jaringan yang baik. Balai Besar Teknologi Energi (B2TE) sudah menggunakan jaringan didalam pelaksanaan aktivitas instansi setiap harinya. Namun sangat disayangkan, pada jaringan B2TE belum dapat dikontrol dengan sempurna. Hal ini menyebabkan timbulnya permasalahan pada jaringan.

Hasil observasi yang penulis lakukan didapatkan beberapa masalah yang dihadapi seperti topologi jaringan yang masih menggunakan pengalamatan IP dengan sistem satu Network. Kemudian, traffic data yang sering mengalami gangguan, traffic jaringan yang belum berjalan secara optimal yang disebabkan karena adanya pembagian beban traffic yang tidak seimbang. Kebutuhan internet yang terkait dengan manajemen bandwidth yang sampai saat ini belum diterapkan dalam jaringan yang membuat konsumsi bandwidth dirasa sangat boros dan tidak berimbang terlebih disaat sedang banyaknya pemakaian internet. Kemudian juga pembagian bandwidth yang diberikan belum sesuai dengan kebutuhan untuk masing-masing user. Selain itu, hak akses untuk semua client pun disamakan dengan yang lainnya. Padahal, ada beberapa client seperti manager, direktur, atau pun divisi lain yang membutuhkan hak akses yang istimewa. Selain itu, dalam pengaksesan internet yang membutuhkan input username dan password, user harus menginputkan username yang berbeda-beda dan hal ini bisa merepotkan user yang terkadang lupa dengan username dan password yang dibuat.

Manajemen jaringan sangatlah dibutuhkan dalam suatu jaringan agar semua proses yang ada dalam jaringan tersebut dapat terkontrol dengan baik. Manajemen jaringan juga dibutuhkan dalam suatu jaringan komputer agar tercipta suatu capaian yang diharapkan yaitu efektifitas dan efisiensi jaringan. Untuk pecapaian hal tersebut, dilakukan perancangan dan implementasi mikrotik router board RB450G untuk manajemen jaringan B2TE - BPPT . perancangan yang dilakukan meliputi basic setting mikrotik (IP address, DNS, mangeh), bandwidth management setting, setting firewall, security, load balancing, dan user management. Dalam proses konfigurasi, digunakan perangkat lunak "winbox" yang dioperasikan pada sistem operasi windows yang nantinya akan dikoneksikan dengan mikrotik router board yang digunakan. Sesuai dengan identifikasi masalah di atas, maka penulis merumuskan permasalahan yang ada yaitu:

1. Bagaimana topologi yang harus diterapkan agar sesuai dengan sistem yang akan diterapkan?

2. Bagaimana mengoptimalkan traffic jaringan agar tidak terjadi overload pada salah satu jalur koneksi?

3. Bagaimana cara menentukan rule untuk setiap traffic data yang mengalir di dalam jaringan? 
4. Bagaimana upaya untuk mengatur hak akses tiap user mengingat kebutuhan tiap user berbeda-beda?

5. Bagaimana untuk mengoptimalkan penggunaan bandwidth agar pendistribusiannya sesuai dengan masing-masing user?

6. Bagaimana cara meminimalisir penggunaan username dan password?

Tujuan dari perancangan mikrotik pada jaringan Balai Besar Teknologi dan Energi adalah sebagai berikut:

1. Merancang topologi jaringan baru pada B2TE - BPPT Serpong.

2. Mengimplementasikan manajemen jaringan dengan membuat Load balancing dengan teknik Fail-Over secara manual, melakukan pengaturan penggunaan Bandwidth, dan melakukan pengaturan terhadap hak akses serta manajemen terhadap user.

3. Menerapkan sistem Single sign on (SSO) untuk penyederhanaan akun.

4. Menghasilkan referensi untuk pengembangan lebih lanjut untuk topik serupa.

\section{METODOLOGI PENELITIAN}

\subsection{Metode Pengumpulan Data}

\subsubsection{Observasi}

Observasi adalah cara pengambilan data dengan menggunakan mata tanpa ada pertolongan alat standar lain untuk keperluan tersebut. (Moh. Nazir,2005:175). Mengumpulkan informasi mengenai kebutuhan sistem (system requirements). Penulis melakukan pengumpulan data dengan cara observasi di tempat penelitian, dalam hal ini adalah Balai Besar Teknologi Energi (B2TE), Badan Pengkajian dan Pusat Teknologi (BPPT). Penulis terjun langsung ke lapangan untuk mengetahui sistem yang sedang berjalan saat ini. Hal ini perlu dilakukan agar penulis dapat melakukan analisis terhadap sistem yang telah berjalan serta menentukan rancangan sistem baru yang akan dibangun agar tetap sesuai dengan sistem yang sudah ada.

\subsubsection{Wawancara}

Penulis menggunakan jenis penelitian dengan wawancara karena penulis melakukan wawancara dengan tatap mukan langsung. Wawancara adalah proses memperoleh data untuk tujuan penelitian dengan cara tanya jawab, sambil bertatap muka kepada pewawancara dengan si penjawab atau responden dengan alat yang dinamakan interview guide (panduan wawancara). (Moh. Nazir.2005:195). Wawancara dilakukan kepada pihak-pihak yang nantinya akan berhubungan dengan aplikasi atau sistem yang akan diterapkan. 
ANALISIS DAN IMPLEMENTASI MIKROTIK ROUTER BOARD...

\subsubsection{Studi Sejenis}

Studi sejenis atau studi pustaka yakni mengumpulkan data primer atau referensi melalui literature, buku, artikel maupun secara online menggunakan media internet untuk mendapatkan referensi yang berhubungan dengan penelitian.

\subsection{Metode Pengembangan Sistem}

Pengembangan sistem merupakan alternatif dalam berapresiasi dalam mendalami suatu kajian ilmu. Namun tetap harus mempunyai landasan dalam pengembangan sistem yang dilakukan. Pada penelitian ini, penulis menggunakan model pengembangan sistem NDLC (Network Development Live Cycle). Menurut Goldman dan Rawles (2004:470), NDLC merupakan model kunci dibalik proses perancangan jaringan komputer. NDLC merupakan model yang mendefinisikan siklus proses pembangunan atau pengembangan sistem jaringan komputer.

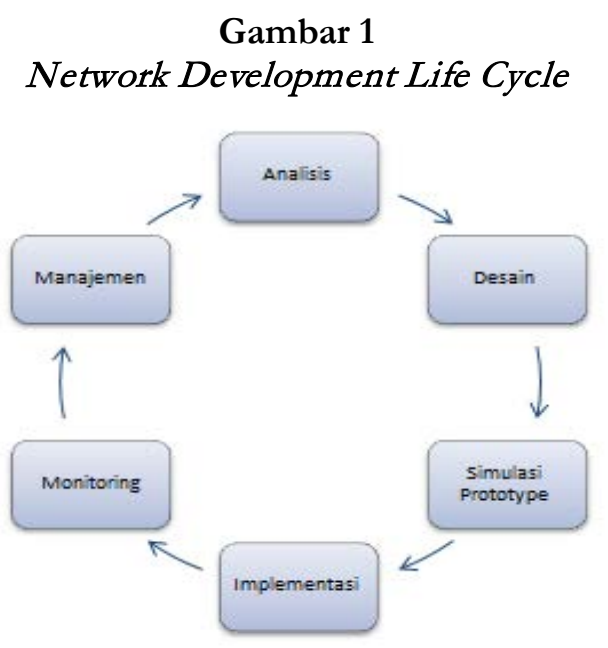

Aktivitas yang dilakukan dalam pengembangan ini meliputi analisis, design, Prototype simulation, implementation, monitoring, management.

a. Analisis, Pada tahap analisis dilakukan analsis sistem yang sedang berjalan, analisis permasalahan, dan analisis kebutuhan.

b. Desain, Pada tahap ini dilakukan perancangan baik desain fisik maupun desain logic terhadap sistem yang dibangun.

c. Simulasi Prototype, Mensimulasikan beberapa sistem dengan menggunakan perangkat VM Ware.

d. Implementasi, Pada tahap implementation, dilakukan beberapa tahapan konfigurasi pada mikrotik router board yang digunakan diantaranya:

1. Membangun router mikrotik yang dalam hal ini mikrotik yang digunakan adalah mikrotik built-in hardware yang dikemas dalam router board dengan tipe RB 450 G. Tahap awal yang 
dilakukan adalah konfigurasi dasar mikrotik yang meliputi penamaan segmen jaringan, pemberian alamat IP, pengaturan Domain Name Server (DNS), dan lain sebagainya.

2. Konfigurasi load balancing dengan menggunakan metode PCC.

3. Konfigurasi bandwidth management dengan menggunakan metote HTB dan PCQ yang diterapkan pada queue tree.

4. Konfigurasi user management.

5. Perancangan sistem SSO (Single sign on).

e. Monitoring, Pada tahapan ini penulis akan melakukan monitoring dan pengujian sejauh mana sistem yang dibangun berjalan dalam mengoptimasi penggunaan mikrotik router board untuk manajemen jaringan.

Manajemen, Management yang dilakukan adalah dengan membuat suatu kebijakan agar sistem yang telah dibangun dapat berjalan dengan baik dan dapat berlangsung lama serta unsur reability terjaga.

\subsection{Mekanisme Kerja dan Kerangka Berpikir Penelitian}

Gambar 2

Mekanisme Kerja

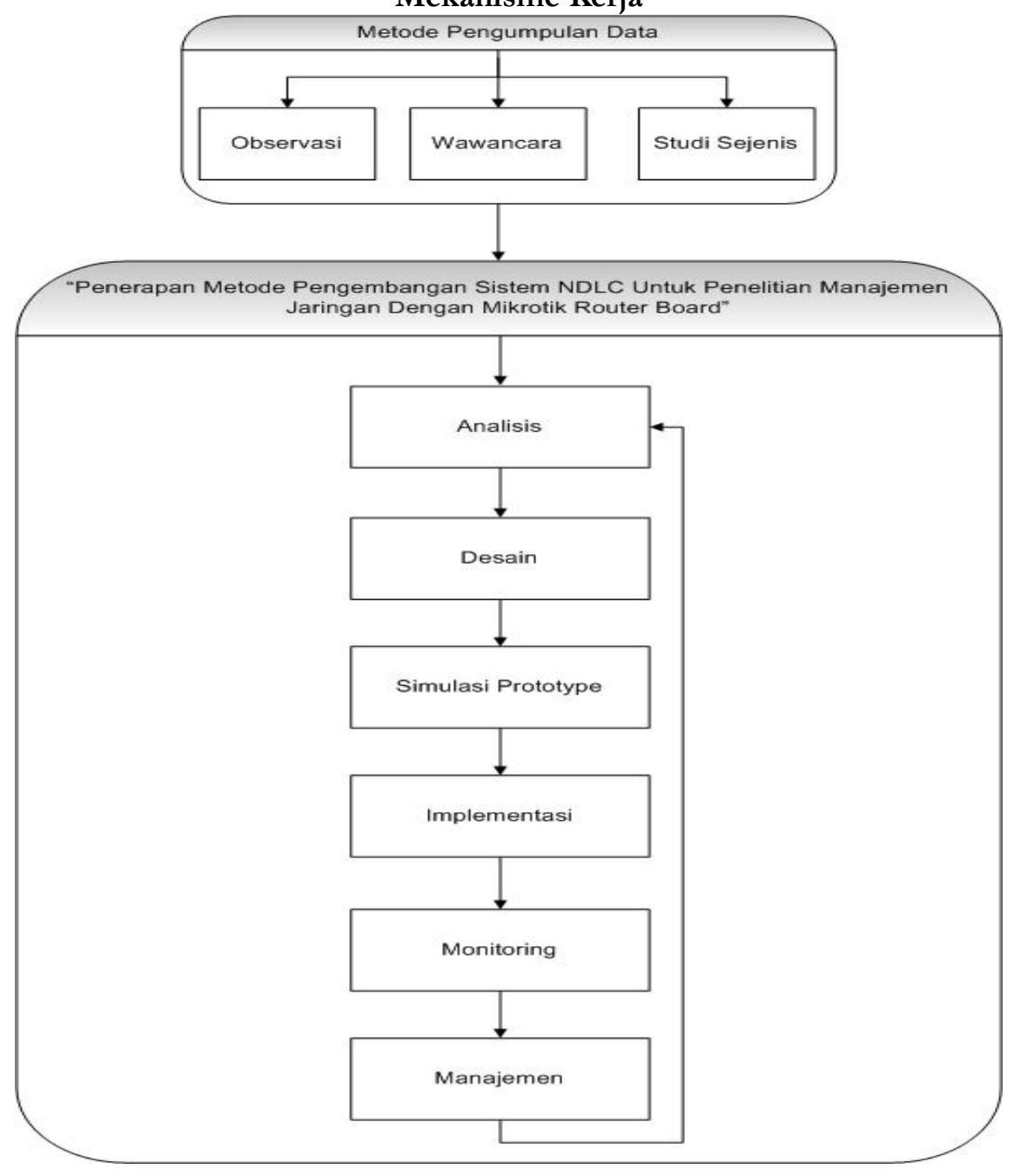


ANALISIS DAN IMPLEMENTASI MIKROTIK ROUTER BOARD...

Gambar 3

Kerangka Berpikir Penelitian

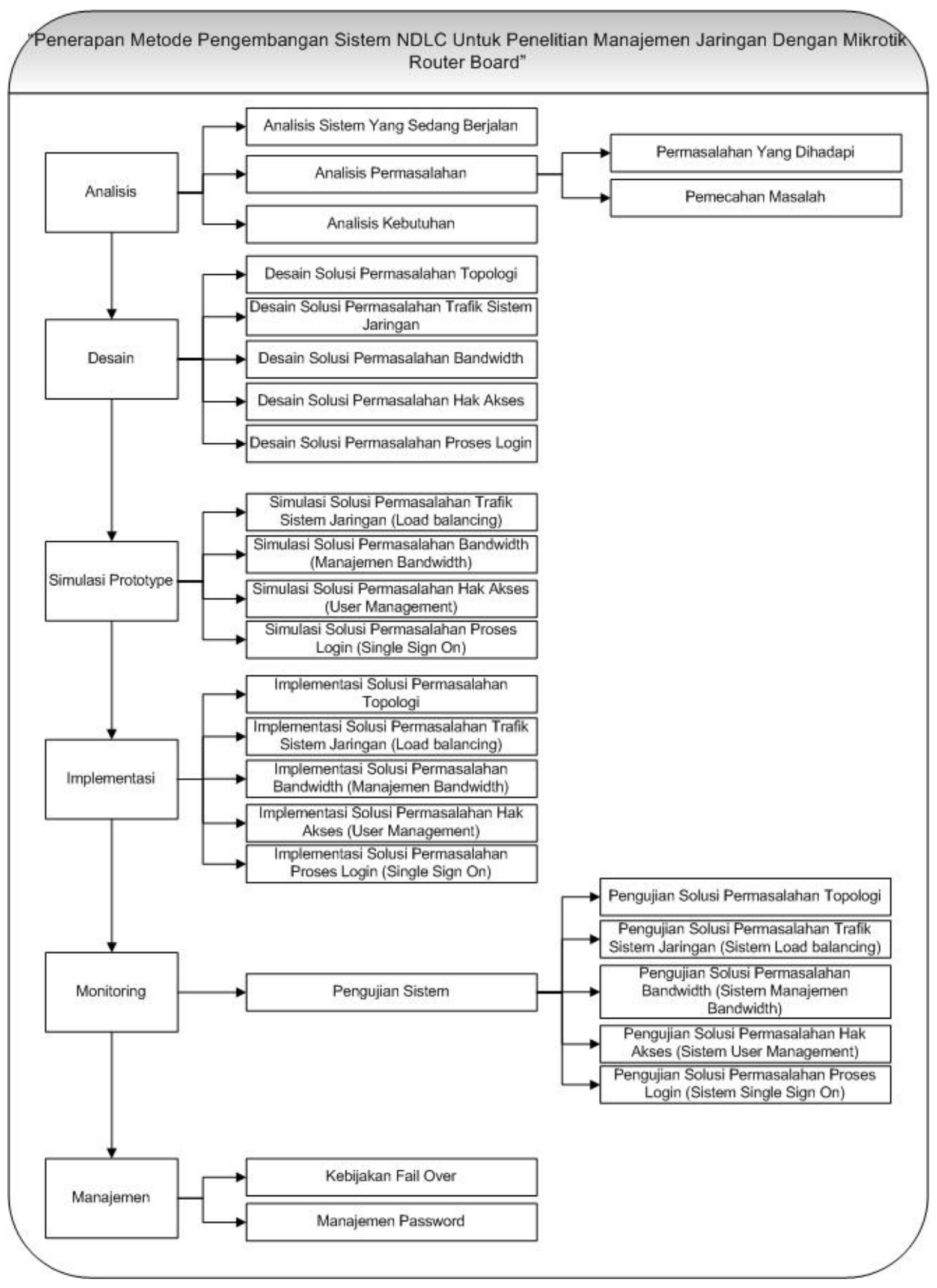




\section{ANALISIS DAN PEMBAHASAN}

\subsection{Analisis}

\subsubsection{Analisis Sistem}

\section{a. Analisis sistem yang sedang berjalan}

Sistem jaringan komputer yang sedang berjalan pada B2TE saat ini terkoneksi dengan dua buah ISP. Masing-masing ISP dihubungkan ke proxy server yang ada di B2TE. Setelah dari proxy server, kemudian dikoneksikan melalui main switch yang selanjutnya akan disambungkan ke jaringan lokal dan jaringan server.

\section{Gambar 4}

\section{Diagram Jaringan B2TE}

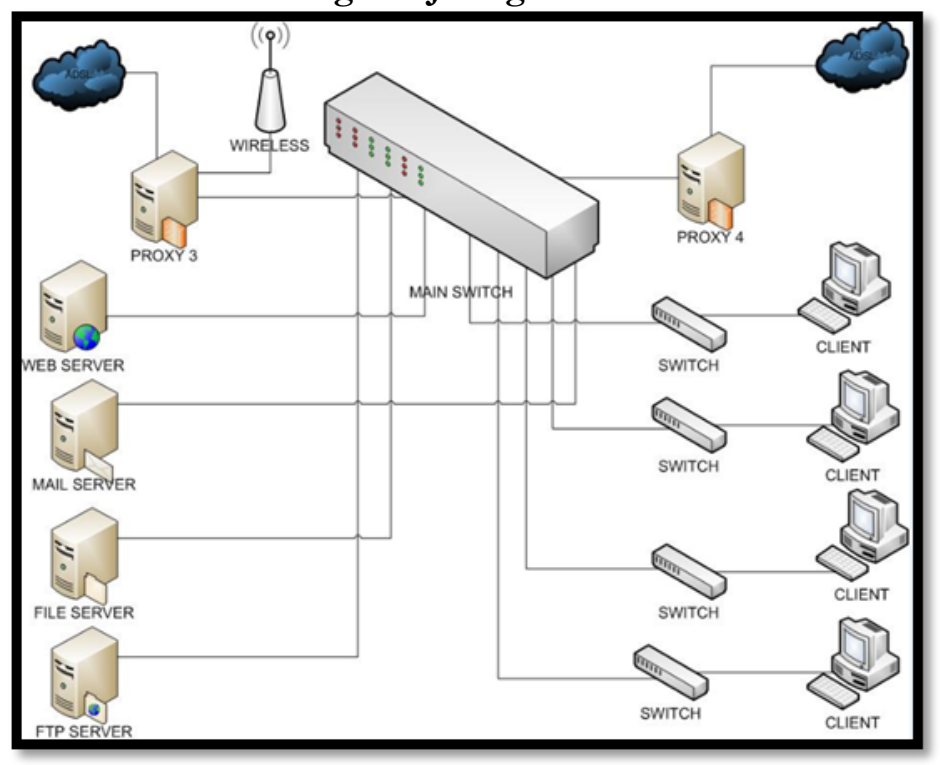

Sumber : Data diolah

Pengalamatan IP yang digunakan dilakukan secara dinamis dengan menggunakan DHCP server yang diberikan oleh server jaringan. Kelas IP yang digunakan adalah IP kelas C, baik untuk client maupun server. Dalam sistem jaringan B2TE, digunakan perangkat lunak IPCop yang difungsikan sebagai proxy yang memakai alamat IP publik ISP 1. Untuk dukungan terhadap manajemen jaringan, digunakan perangkat lunak Zentyal.

\section{b. Analisis permasalahan}

Permasalahn yang timbul dari topologi adalah posisi client (user), dan server berada pada satu posisi yang sejajar, dan pada sistem jaringan B2TE masih dalam satu Network artinya belum ada manajemen untuk sisi maintenance dan pengelolaan dari segi server. Untuk menangani hal tersebut, dilakukan perancangan topologi jaringan baru menggunakan perangkat Mikrotik. Berkaitan dengan trafik sistem jaringan, permasalahan yang dihadapi adalah adanya ketidakseimbangan pembagian trafik, sehingga menyebabkan waktu tanggap menjadi lama dan terjadi overload 
ANALISIS DAN IMPLEMENTASI MIKROTIK ROUTER BOARD...

pada salah satu jalur data. Pemecahan masalah yang diberikan adalah dengan menerapkan sistem load balancing menggunakan metode PCC dan fail over. Untuk bandwidth, permasalahan yang timbul adalah tidak adanya pembagian bandwidth. Untuk itu perlu diterapkan manajemen bandwidth dengan metode HTB untuk melimitasi bandwidth dan metode PCQ untuk membatasi data rate. Pada permasalahan hak ases, pemberian hak akses yang tidak melakukan pemblokiran apabila terdapat user yang membawa notebook dan menghubungkannya ke kabel UTP yang tersedia. Sehingga user tersebut dapat langsung terhubung dengan jaringan LAN dan internet. Untuk itu, diterapkan sistem hotspot yang dapat mengatur hak akses user. Permasalahan proses login yang timbul adalah banyaknya penggunaan username dan password. dalam hal meminimalisir username dan password, diterapkan sistem single sign on.

\section{c. Analsisi kebutuhan}

Kebutuhan terhadap sistem yang akan dibangun terkait dengan pemecahan terhadap permasalahan yang ada. Baik itu kebutuhan perangkat keras, maupun perangkat lunak.

Tabel 1

Kebutuhan Perangkat Lunak

\begin{tabular}{|c|c|c|c|}
\hline No & Software & Fungsi & Analisis Kebutuhan \\
\hline 1 & $\begin{array}{l}\text { Vmware Workstation } \\
7.0 .0\end{array}$ & $\begin{array}{l}\text { Sistem Operasi untuk } \\
\text { Simulasi }\end{array}$ & $\begin{array}{l}\text { Kebutuhan perancangan load } \\
\text { balancing, manajemen bandwidth, } \\
\text { dan user management }\end{array}$ \\
\hline 2 & Mikrotik RouterOS & $\begin{array}{l}\text { Sistem Operasi Mikrotik } \\
\text { untuk simulasi }\end{array}$ & $\begin{array}{l}\text { Kebutuhan perancangan load } \\
\text { balancing, manajemen bandwidth, } \\
\text { dan user management }\end{array}$ \\
\hline 3 & Microsoft Office Visio & $\begin{array}{l}\text { Tools untuk desain } \\
\text { Topologi jaringan dan } \\
\text { diagram alir data }\end{array}$ & $\begin{array}{l}\text { Kebutuhan } \quad \text { perancangan } \\
\text { topologi }\end{array}$ \\
\hline 4 & Winbox 2.2.18 & $\begin{array}{l}\text { Tools untuk remote } \\
\text { sistem }\end{array}$ & $\begin{array}{l}\text { Kebutuhan perancangan load } \\
\text { balancing, manajemen bandwidth, } \\
\text { dan user management. }\end{array}$ \\
\hline 5 & Graphing & Tools monitoring & $\begin{array}{l}\text { Kebutuhan perancangan load } \\
\text { balancing } \\
\text { bandwidth. }\end{array}$ \\
\hline 6 & Torch & $\begin{array}{l}\text { Real Time } \\
\text { Monitoring }\end{array}$ & $\begin{array}{l}\text { Kebutuhan perancangan load } \\
\text { balancing } \\
\text { bandwidth. }\end{array}$ \\
\hline 7 & Zimbra Mail Server & $\begin{array}{l}\text { Digunakan untuk mail } \\
\text { server B2TE dan juga } \\
\text { sebagai OpenLDAP }\end{array}$ & $\begin{array}{l}\text { Kebutuhan perancangan sistem } \\
\text { SSO. }\end{array}$ \\
\hline 8 & Freeradius & Radius Server & $\begin{array}{l}\text { Kebutuhan perancangan sistem } \\
\text { hotspot dan SSO. }\end{array}$ \\
\hline 9 & Open SSL & $\begin{array}{l}\text { Pembuatan } \\
\text { botspot }\end{array}$ & $\begin{array}{l}\text { Kebutuhan perancangan sistem } \\
\text { hotspot. }\end{array}$ \\
\hline
\end{tabular}

Sumber: Data diolah 
Tabel 2

Kebutuhan Perangkat Keras

\begin{tabular}{|c|l|l|}
\hline No. & \multicolumn{1}{|c|}{ Nama Hardware } & \multicolumn{1}{c|}{ Spesifikasi } \\
\hline 1 & Mail Server & Motherboard : Asus P5GC-VM \\
& & Processor : Core Duo E7400 2.8 GHz \\
& & RAM : 2 GB \\
& & Hardisk : 320 GB \\
& & OS : Ubuntu 8.04 LTS \\
\hline 2 & Radius Server & Motherboard : Asus K-40-IN \\
& & Processor : Core 2 Duo T6600 2.2 GHz \\
& & RAM : 2 GB \\
& & Hardisk : 320 GB \\
& & OS : Ubuntu 12.0 LTS \\
\hline 3 & Mikrotik Router Board & Type $:$ RB450G \\
& & Jumlah gigabit port : 5 buah \\
& & Processor : Atheros AR7161 680Mhz \\
& & RAM : 256 MB \\
& & Router OS Level : 4 \\
\hline
\end{tabular}

Sumber : Data diolah

\subsubsection{Desain}

Berdasarkan solusi yang diberikan terhadap permasalahan topologi, yaitu dilakukan perancangan topologi ulang menggunakan topologi tree

Gambar 5

Desain Topologi Jaringan B2TE Untuk Sistem yang Akan Dibangun

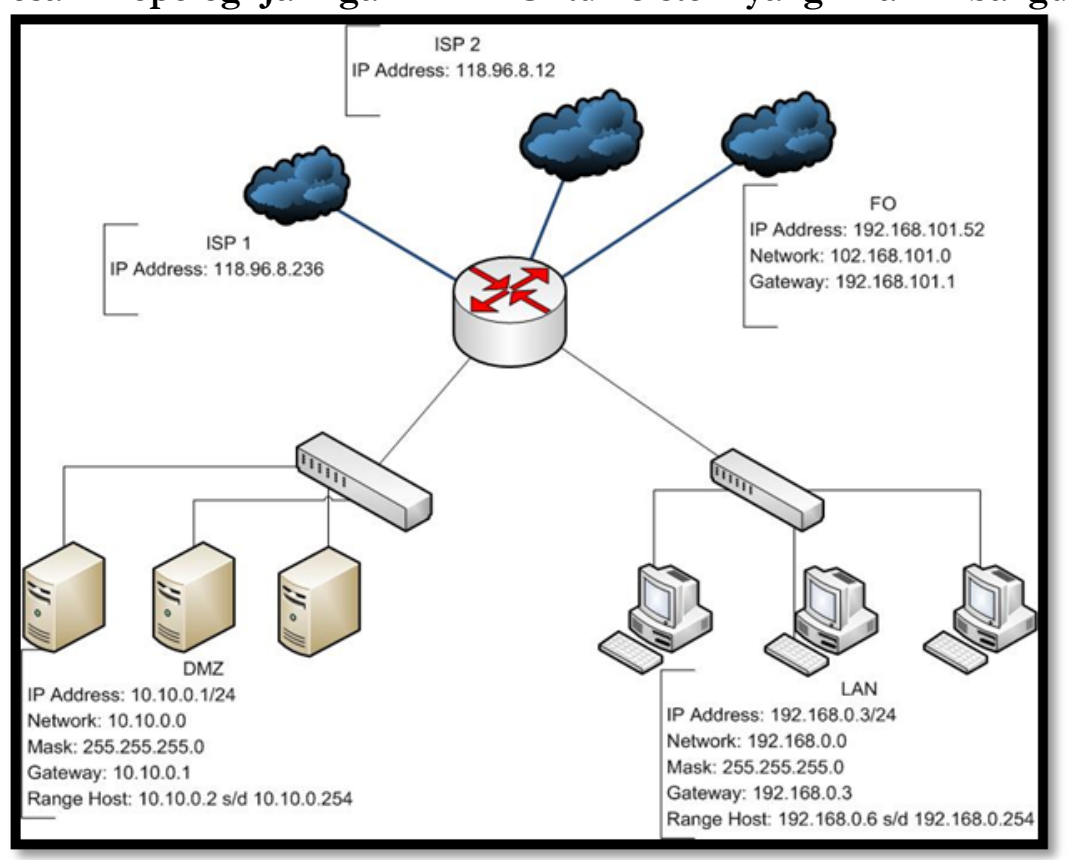

Desain load balancing yang dilakukan didasarkan pada solusi permasalahan pada trafik sistem jaringan yaitu menggunakan metode Per Connection Classifier (PCC). Load balancing yang diterapkan menggunakan parameter pemisahan trafik PCC Both-addressand-ports. Karena Trafik ISP yang digunakan berbeda (2MB, 2MB dan 4MB), maka 
ANALISIS DAN IMPLEMENTASI MIKROTIK ROUTER BOARD ...

beban trafik dibagi menjadi 4 bagian dengan perbandingan 1:1:2. Pengaturan bandwidth menggunakan quee tree dengan metode Per Connection Queue (PCQ) dimungkinkan untuk membatasi maksimal data rate untuk setiap sub-queue (pcq-rate) dan jumlah paket data (pcq-limit). Untuk desain logic PCQ type yang diterapkan dapat dilihat pada tabel dibawah ini.

Tabel 3

Desain Logic PCQ Type

\begin{tabular}{|l|l|l|l|l|}
\hline No & Kind & Name & Pcq-rate & Pcq-limit \\
\hline 1 & PCQ & Pcqdown & 1500 & 50 \\
\hline 2 & PCQ & Pcqpload & 0 & 50 \\
\hline
\end{tabular}

Sumber : Data diolah

Untuk metode HTB diterapkan beberapa rule yang berkaitan dengan batasan limit (limit-at) dan maksimum limit (max-limit) bandwidth yang diberikan. Berikut rule yang disajikan dalam bentuk tabel.

Tabel 4

Desain Logic Penggunaan Alokasi Bandwidth

\begin{tabular}{|c|c|c|c|c|c|c|c|}
\hline \multirow[b]{2}{*}{ No } & \multirow[b]{2}{*}{ Rule } & \multicolumn{2}{|c|}{ Alokasi Bandwidth } & \multicolumn{3}{|c|}{ Burst } & \multirow[b]{2}{*}{ Priority } \\
\hline & & Limit At & $\begin{array}{l}\text { Max } \\
\text { Limit }\end{array}$ & $\begin{array}{l}\text { Burst } \\
\text { Limit }\end{array}$ & $\begin{array}{c}\text { Burst } \\
\text { Threshold }\end{array}$ & $\begin{array}{l}\text { Burst } \\
\text { Time }\end{array}$ & \\
\hline 1 & $D O W N L O A D$ (Parent) & - & $8 \mathrm{MBps}$ & - & - & - & 8 \\
\hline 2 & down-local (Child) & $512 \mathrm{KBps}$ & 4MBps & 8Mbps & $\begin{array}{c}2256 \mathrm{KBp} \\
\mathrm{s}\end{array}$ & $8 \mathrm{~s}$ & 3 \\
\hline 4 & UPLOAD (Parent) & - & $800 \mathrm{KBps}$ & - & - & - & 8 \\
\hline 5 & up-local (Child) & $200 \mathrm{KBps}$ & $400 \mathrm{KBps}$ & $800 \mathrm{Kbps}$ & $300 \mathrm{Kbps}$ & $8 \mathrm{~s}$ & 3 \\
\hline
\end{tabular}

Seperti yang telah dijabarkan, user management yang diterapkan adalah dengan memberlakukan sistem hotspot pada sistem jaringan B2TE. Berikut adalah desain IP address yang digunakan untuk sistem hotspot.

Tabel 5

Desain Logic Sistem Hotspot

\begin{tabular}{|c|c|c|c|c|}
\hline Name & Interface & Address Pool for user & DNS Name & Address pool for guest \\
\hline \multirow{3}{*}{ Hotspot1 } & \multirow{2}{*}{ local } & local & login.b2te.bppt.go.id & $(192.168 .0 .20-$ \\
& & $(192.168 .0 .6-$ & & $192.168 .0 .30)$ \\
\hline
\end{tabular}

Berikut adalah rancangan dari pemecahan masalah proses login dengan sistem Single sign on yang akan diterapkan pada sistem jaringan B2TE.

Tabel 6

Desain Logic Sistem SSO

\begin{tabular}{|c|l|l|c|}
\hline No & Perangkat & Type & IP Address \\
\hline 1 & Mikrotik & Router Board & 192.168 .0 .3 \\
\hline 2 & $\begin{array}{l}\text { Radius } \\
\text { Server }\end{array}$ & FreeRadius & 10.10 .0 .8 \\
\hline 3 & LDAP & Zimbra & 10.10 .0 .9 \\
\hline
\end{tabular}

Sumber: Data diolah 


\subsubsection{Simulasi Prototype}

Pada tahap ini, dilakukan simulasi atau uji coba dari sistem yang dibangun. Untuk simulasi load balancing dengan metode PCC, manajemen bandwidth, dan user management penulis menggunakan VM Ware Workstation yang di dalamnya diinstall mikrotik Router OS versi 3.3

\subsubsection{Implementasi}

Implementasi yang dilakukan sebagai solusi permasalahan topologi adalah melakukan konfigurasi dari sisi router mikrotik. Hal tersebut dilakukan agar semua segmen yang terdapat dalam topologi jaringan dapat terhubung satu dengan yang lainnya. Proses menghubungkan semua perangkat tersebut adalah melakukan inisialisasi interface, pemberian IP address, pembuatan DHCP server, dan konfigurasi DNS server.

Implementasi yang dilakukan untuk permasalahan trafik sistem jaringan (Load Balancing) adalah dengan menentukan kebijakan mangle yang dilakukan untuk menentukan paket data yang datang dari suatu interface tertentu yang akan diproses. Fungsi mangle sendiri adalah untuk menandai (marking) paket agar dapat diarahkan sesuai dengan rule routing yang ada. Proses marking dilakukan mulai dari marking koneksi, routing mark, sampai pada marking untuk metode yang digunakan yaitu PCC (Per Connection Classifier). Setelah dilakukan marking, maka harus dibuat aturan baru pada routing table agar dapat melewatkan paket data ke gateway yang sesuai dengan marking yan telah dibuat. Kemudian terakhir dilakukan proses NAT untuk mengubah alamat sumber paket agar dapat terkoneksi dengan jaringan internet. Sama halnya seperti implementasi load balancing, untuk manajemen bandwitdth juga harus ditetapkan kebijakan mangle untuk melakukan marking pada proses queuing. Setelah dilakukan proses marking, dilakukan penentuan queue type, yang dalam hal ini digunakan queue type PCQ (Per Connection Queue). Tahap selanjutnya adalah konfigurasi queue dengan menggunakan queue tree dengan metode HTB untuk melimitasi penggunaan bandwidth. Sebelum melakukan proses quening dengan metode HTB, terlebih dahulu melakukan perhitungan batasan bandwidth (limit-at dan maxlimit) baik untuk download maupun upload.

a. Download

Untuk koneksi download, bandwidth yang tersedia adalah $8000 \mathrm{KBps}$. Limit-at yang diberikan ke client adalah sebesar 512KBps, itu artinya dalam keadaan terburuk, client akan mendapatkan bandwidth sebesar limit-at yang telah ditentukan yaitu 512KBps (Committed Information Rate (CIR)). Sedangkan untuk nilai max-limit yang diberikan adalah sebesar 4M, itu artinya jika masih ada bandwidth yang tersisa 
ANALISIS DAN IMPLEMENTASI MIKROTIK ROUTER BOARD...

setelah semua client mencapai limit-at maka client akan mendapatkan bandwidth sebesar max-limit yang telah ditentukan yaitu 4M (Maximal Information Rate (MIR)).

b. Upload

Untuk koneksi upload, tersedia bandwidth sebesar 800Kbps. Nilai limit-at yang dapat diberikan adalah 200KBps dan untuk nilai max-limit sebesar 400KBps. Implementasi yang dilakukan sebagai solusi permasalahan hak akses adalah dengan membuat hotspot SSL certificate. SSL certificate digunakan karena sistem hotspot yang digunakan menggunakan metode autentikasi HTTPS. Setelah itu dibuat hotspot server profile yang digunakan untuk menyimpan konfigurasi umum dari hotspot server. Kemudian dibuat hotspot user profile untuk menyimpan konfigurasi umum dari user-user hotspot yang digunakan juga untuk grouping beberapa user. Dan terakhir membuat hotspot user yang merupakan halaman dimana parameter username, password, dan profile dari user disimpan. Beberapa limitasi juga bisa ditentukan di halaman user. Dalam proses imlplementasi Single Sign On, yang dilakukan adalah pengintegrasian antara sistem hotspot dengan radius server dan pengintegrasian antara radius server dengan LDAP server.

\subsubsection{Monitoring}

NDLC mengkategorikan proses pengujian pada fase monitoring (pengawasan). Hal ini dikarenakan pengawasan sistem yang sudah dibangun hanya dapat dilakukan jika sistem sudah dapat bekerja sesuai dengan kebutuhan.

a. Pengujian Solusi Permasalahan Topologi

Pengujian dilakukan dengan melakukan proses ping ke gateway masing-masing segmen jaringan. Berikut hasil proses ping yang dilakukan melalui terminal mikrotik.

Gambar 6

Pengujian Ping Ke Semua Interface

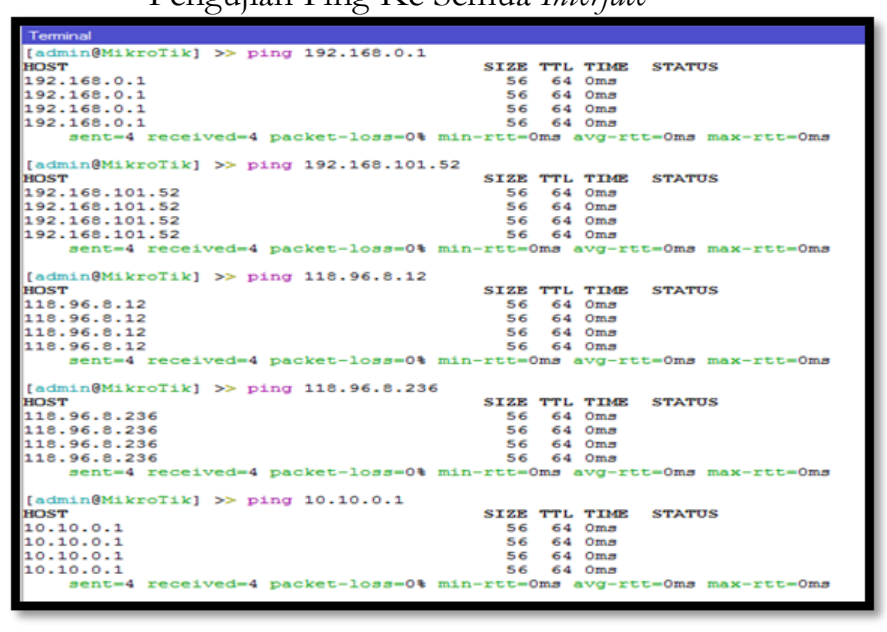

Sumber : Data diolah 
b. Pengujian Solusi Permasalahan Trafik Sistem Jaringan

Pengujian load balancing (solusi permasalahan trafik jaringan) dilakukan dengan tujuan untuk mengetahui waktu tanggap dan pemerataan beban trafik dari sistem yang dihasilkan.

1. Perbandingan Waktu Akses Sebelum dan Sesudah Implementasi

a. Kirim data dengan besar data $5 \mathrm{MB}$

Tabel 7

Perbandingan Durasi Kirim Data Sebelum dan Setelah Implementasi

\begin{tabular}{|l|c|c|}
\hline \multirow{2}{*}{} & \multicolumn{2}{|c|}{ Waktu Rata-rata } \\
\cline { 2 - 3 } & Jam Sibuk & Jam Istirahat \\
\hline Sebelum Implementasi & 7.68 menit & 3.11 menit \\
\hline Sesudah Implementasi & 2.72 menit & 1.07 menit \\
\hline Selisih & 4.96 menit & 2.04 menit \\
\hline
\end{tabular}

Sumber : Data diolah

b. Upload file gambar dengan besar data $100 \mathrm{MB}$.

Tabel 8

Perbandingan Durasi Upload Data Sebelum dan Setelah Implementasi

\begin{tabular}{|l|c|c|}
\hline \multirow{2}{*}{} & \multicolumn{2}{|c|}{ Waktu Rata-rata } \\
\cline { 2 - 3 } & Jam Sibuk & Jam Istirahat \\
\hline Sebelum Implementasi & 35.45 menit & 29.28 menit \\
\hline Sesudah Implementasi & 24.26 menit & 21.0 menit \\
\hline Selisih & 11.24 menit & 8.28 menit \\
\hline
\end{tabular}

Sumber : Data diolah

c. Download data dengan besar data $100 \mathrm{MB}$

Tabel 9

Perbandingan Durasi Download Data Sebelum dan Setelah Implementasi

\begin{tabular}{|l|c|c|}
\hline \multirow{2}{*}{} & \multicolumn{2}{|c|}{ Waktu Rata-rata } \\
\cline { 2 - 3 } & Jam Sibuk & Jam Istirahat \\
\hline Sebelum Implementasi & 33.61 menit & 25.57 menit \\
\hline Sesudah Implementasi & 8.93 menit & 5.94 menit \\
\hline Selisih & 24.68 menit & 19.63 menit \\
\hline
\end{tabular}

Sumber : Data diolah 
2. Pemerataan beban trafik jaringan

\section{Gambar 7}

Pembagian Beban Trafik Pada Load balancing Dengan Metode PCC

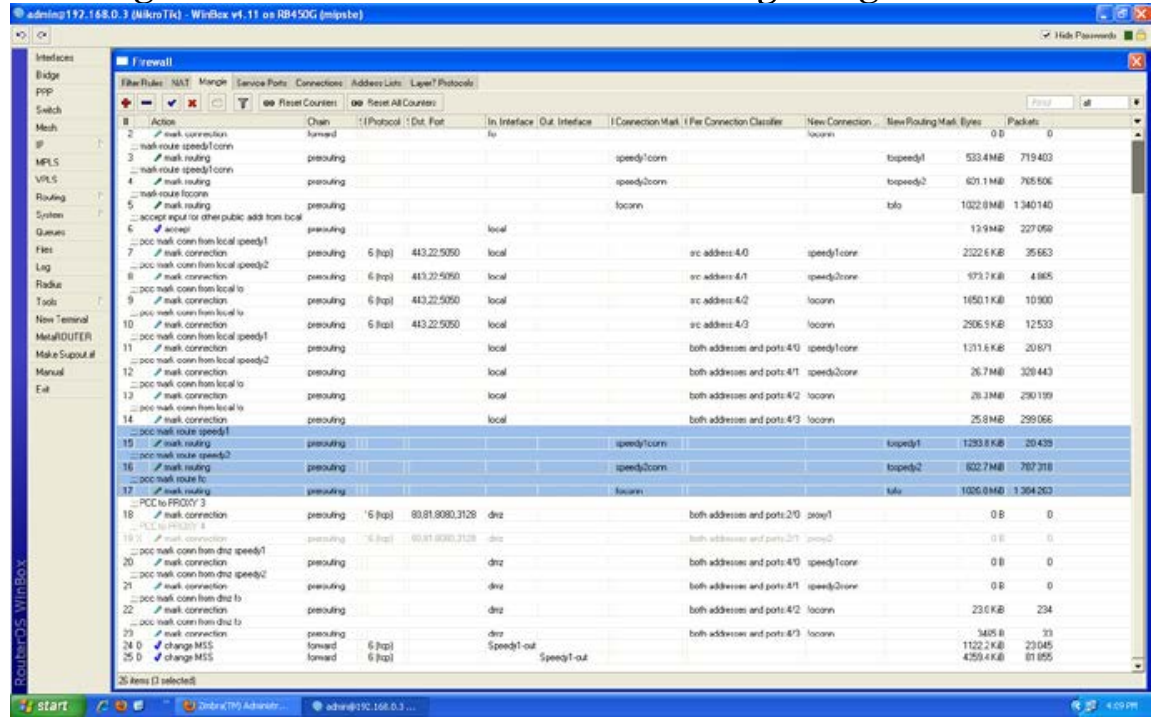

Sumber : Data diolah

a. Pengujian Solusi Permasalahan Bandwidth

Pengujian yang dilakukan adalah dengan memonitoring proses yang dihasilkan dari penerapan metode PCQ dan metode HTB.

\section{Gambar 8}

Proses Download Setelah Dilakukan Manajemen Bandwidth

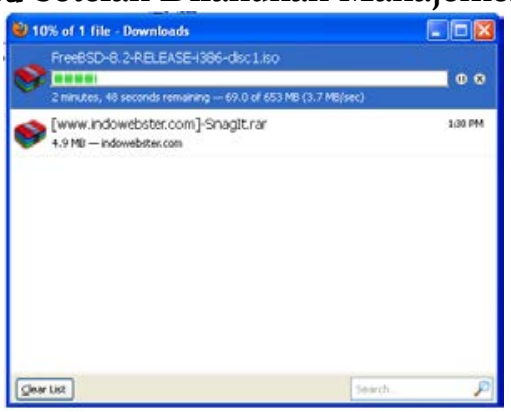

Dari gambar di atas dapat dilihat bahwa waktu tanggap untuk proses download setelah implementasi lebih cepat dibandingkan dengan waktu tanggap sebelum implementasi. Hal tersebut terjadi karena pada sistem yang dibangun, diterapkan manajemen bandwith dimana user pada kondisi tertentu pada proses download akan mendapatkan bandwith maksimal sebesar 4Mbps.

b. Pengujian Solusi Permasalahan Hak Akses (Sistem Hotspot)

Pengujian yang dilakukan adalah apabila user ingin terhubung dengan internet, user harus mengakses halaman login terlebih dahulu. Untuk 
mengakses halaman login, user harus memasukkan alamat https://login.b2te.bppt.go.id

Gambar 9

Hotspot Login Page

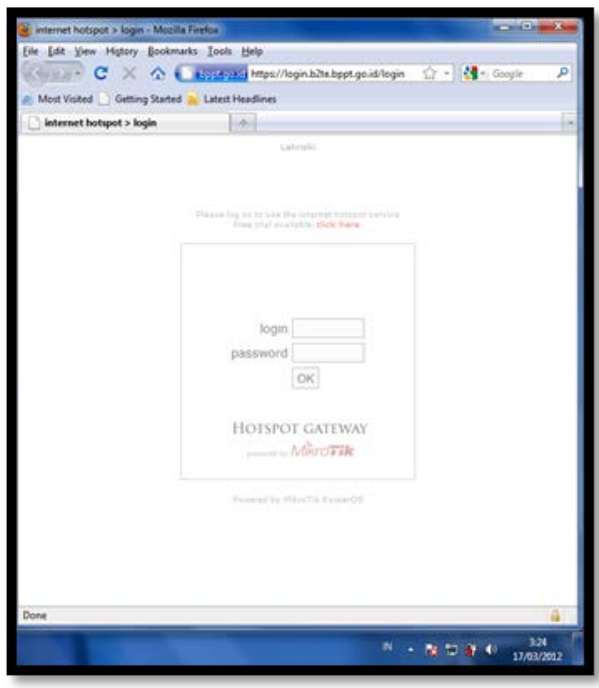

Sedangkan untuk user yang diluar lingkup B2TE (guest) untuk dapat mengakses internet tidak perlu memasukkan username dan password. User tamu (guest) hanya perlu mengklik kalimat "click here" yang terdapat diatas form login setelah itu user tamu (guest) akan langsung mendapatkan alamat IP dan langsung terhubung dengan internet. Alamat IP yang diberikan untuk guest sifatnya terbatas

Gambar 10

Status Login Untuk User Tamu (Guest)

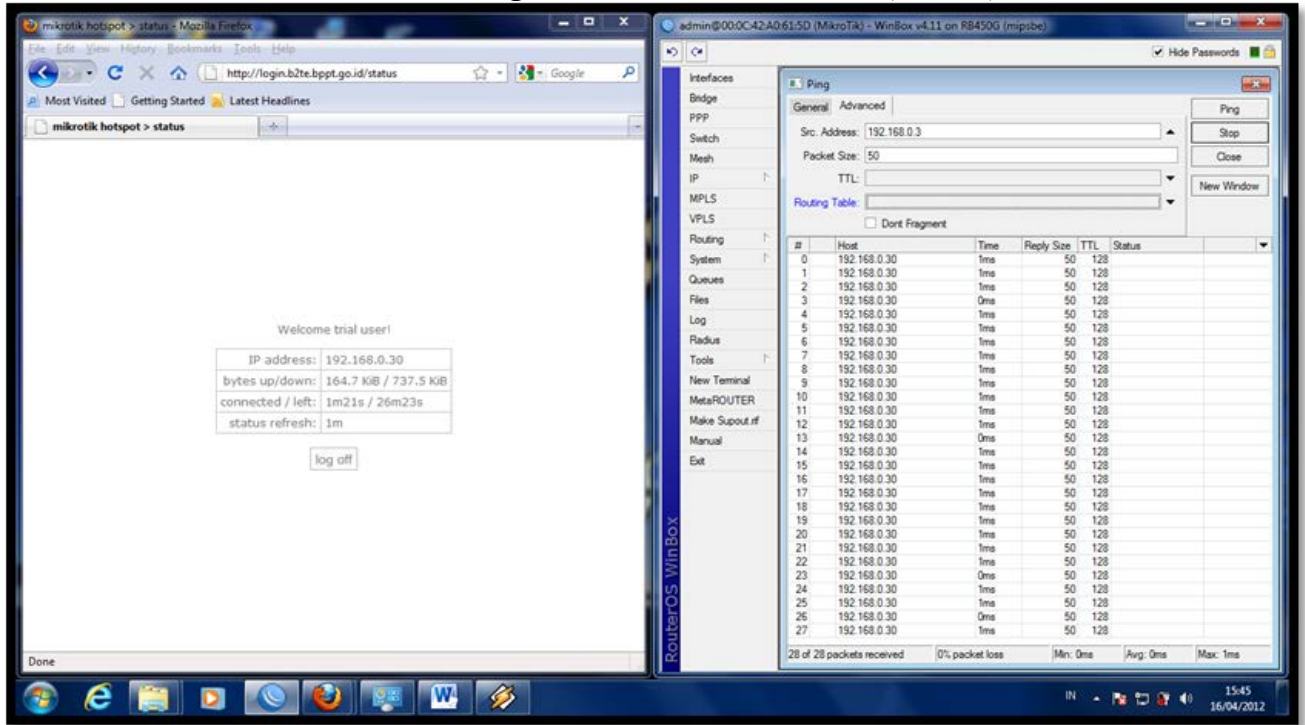


ANALISIS DAN IMPLEMENTASI MIKROTIK ROUTER BOARD..

c. Pengujian Solusi Permasalahan Proses Login

Pengujian yang dilakukan untuk sistem SSO adalah dengan melakukan proses login. Apabila user melakukan kesalahan dalam memasukkan username ataupun password, akan muncul tulisan "invalid username or password"

Gambar 11

Invalid Username Or Password

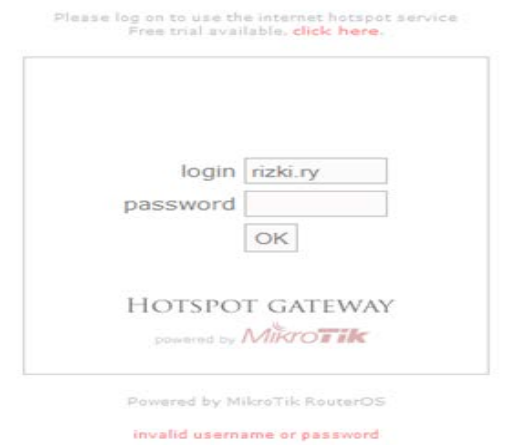

Apabila terdapat user yang mempunyai username yang tidak tersimpan di dalam LDAP yang dalam hal ini adalah zimbra, maka radius akan memberikan respon ke sistem hotspot dengan memunculkan tulisan "Radius Server Is Not Responding”

Gambar 12

Radius Server Is Not Responding

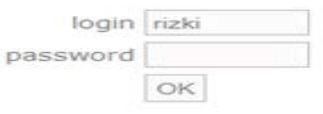

HOTSPOT GATEWAY

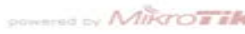

\subsubsection{Manajemen}

Berdasarkan pemantauan terhadap sistem yang sudah berjalan berikut adalah beberapa kebijakan yang diterapkan dalam sistem jaringan B2TE terkait permasalahan yang sudah ditangani.

a. Kebijakan Routes dengan Mekanisme Fail Over

Agar load balancing yang telah diterapkan bisa berjalan lebih optimal, penulis membuat suatu kebijakan untuk membuat suatu rule routing Fail Over yang berguna untuk pengalihan akses koneksi internet ke koneksi yang lain apabila terjadi dissconnection pada salah satu ISP. Kebijakan diatas akan membuat router selalu mengecek kondisi kepada tiap-tiap gateway dengan cara melakukan ping ke tiap- 
tiap gateway dan memberikan prioritas jarak respon pada tiap gateway sehingga apabila salah satu gateway tidak me-reply komunikasi ping dari router, maka router akan menganggap gateway tersebut dalam kondisi down dan akan mengalihkan koneksi ke gateway yang lainnya yang masih berjalan dengan baik.

\section{Gambar 13}

\section{Routing Table}

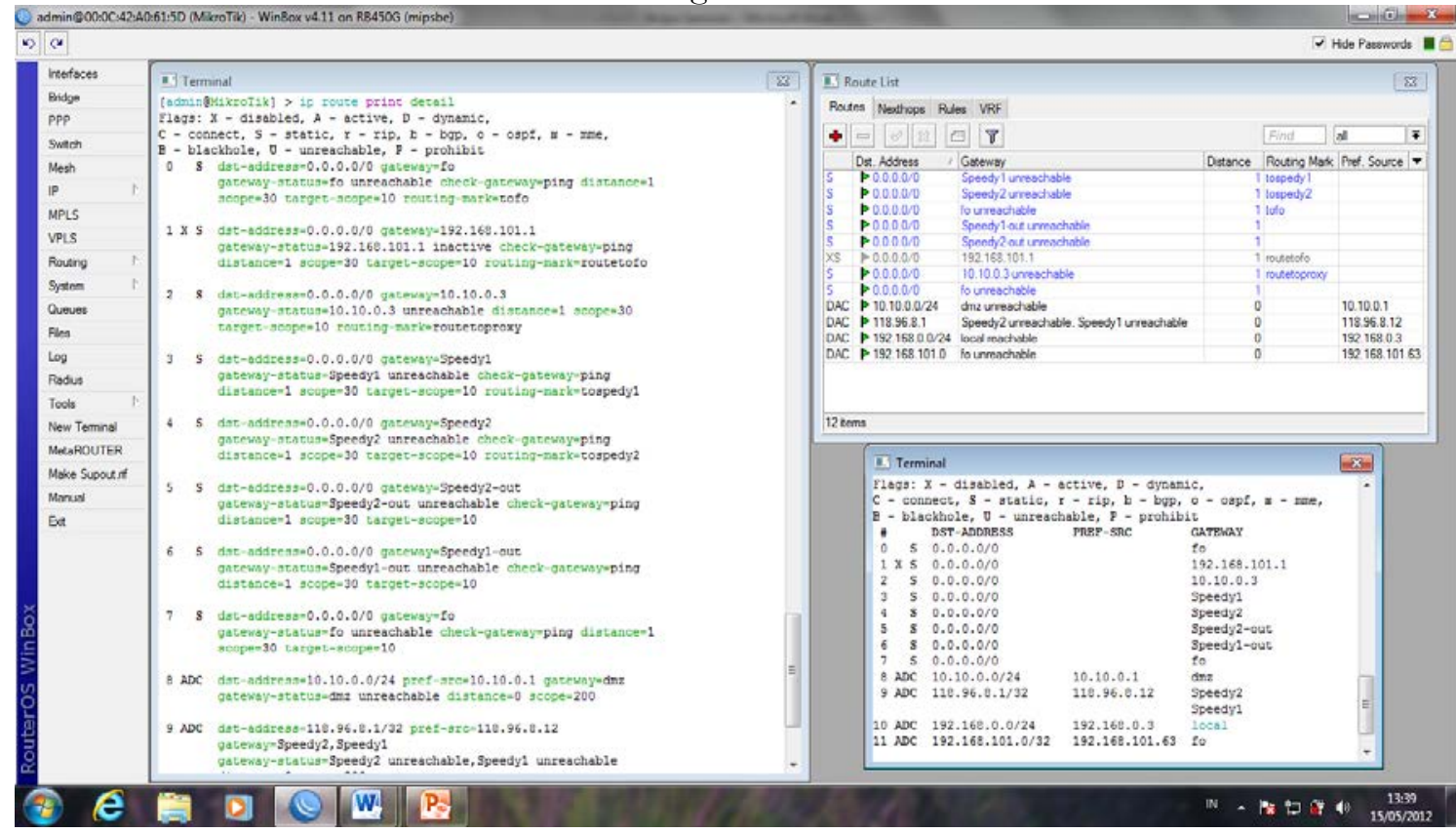

b. Manajemen Password

Password merupakan kode-kode rahasia yang harus dijaga keamanannya. Banyak hal negatif yang dapat terjadi ketika password bocor ketangan orang lain. Maka dari itu, perlu dilakukan suatu manajemen password agar tidak terjadi hal yang tidak diinginkan pada sistem jaringan yang telah dibangun. Manajemen password yang diberlakukan antara lain:

a. Tidak menggunakan default password yang diberikan.

b. Melakukan perubahan password secara berkala, karena semakin sering merubah password akan semakin baik dan semakin aman.

c. Penggunaan password yang kuat saat dilakukan perubahan password. semakin panjang password maka akan semakin kuat keamanan password tersebut.

\subsection{Pembahasan}

\subsubsection{Evalusi Topologi}

Dari hasil pemantauan terhadap implementasi topologi, dapat dilihat bahwa sistem sudah berjalan dengan baik. Semua segmen jaringan yang ada dalam topologi sudah terhubung satu dengan yang lain. Kemudian juga dengan adanya pemisahan antara IP client dan IP server, topologi baru yang sudah diterapkan dapat dengan 
ANALISIS DAN IMPLEMENTASI MIKROTIK ROUTER BOARD ...

mudah untuk dikelola sehingga dengan implementasi yang sudah diterapkan dirasa sudah cukup.

\subsubsection{Evaluasi Sistem Load balancing (Solusi Permasalahan Trafik Sistem Jaringan)}

Berdasarkan dari pengujian sistem yang dilakukan terkait dengan solusi permasalahan trafik sistem jaringan (load balancing), didapat hasil sebagai berikut

a. Sistem load balancing dapat memperkecil waktu tanggap, baik untuk proses upload maupun download pada waktu jam sibuk dan jam istirahat. (merujuk pada table 7 , table 8 , dan table 9).

b. Sistem load balancing dengan metode PCC yang diterapkan dapat menangani permasalahan terjadinya overload pada salah satu jalur internet. Dengan perbandingan PCC yang telah dibuat pemeratan beban trafik jadi lebih merata (merujuk pada gambar 7).

\subsubsection{Evaluasi Sistem Manajemen Bandwidth (Solusi Permasalahan Bandwidth)}

Dari hasil pengujian terhadap sistem manajemen bandwidth yang telah dilakukan (merujuk pada tabel 7, tabel 8, dan tabel 9) dapat dikatakan bahwa sistem manajemen bandwidth sudah dapat menangani permasalahan yang berkaitan dengan bandwidth. Sehingga waktu download ataupun upload yang dilakukan oleh user menjadi lebih cepat. Selain itu dengan adanya pengaturan terhadap alokasi bandwidth yang tersedia, user akan mendapatkan bandwidth yang merata, sehingga tidak terjadi lagi tumpang tindih terhadap penggunaan bandwidth.

Penanganan yang dilakukan adalah dengan melakukan pembagian bandwith yang sesuai dengan kebutuhan. Agar proses manajemen bandwridth dapat berjalan lebih optimal diperlukan adanya peambahan rule yang dapat mengklasifikasikan penggunaan bandwidth lokal dan internasional.

\subsubsection{Evaluasi Sistem Hotspot (Solusi Permasalahan Hak Akses)}

Sistem hotspot yang merupakan solusi permasalahan hak akses sudah diterapkan dalam sistem jaringan B2TE dan sudah berjalan dengan baik (merujuk pada gambar 9). Sistem hotspot yang diterapkan juga difungsikan untuk mengatur penggunaan akses internet tiap-tipa user. Dengan diterapkannya sistem hotspot dirasa sudah cukup untuk menangani permasalahan hak akses yang sebelumnya terjadi.

\subsubsection{Evalusi Sistem Single sign on (Solusi Permasalahan Proses Login)}

Sistem SSO yang diterapkan merupakan solusi dari permasalahan proses login yang menggunakan banyak username dan password. Dengan adanya sistem SSO, permasalahan tersebut sudah berhasil teratasi. Pada sistem yang ada sekarang, untuk mengakses hotspot, user hanya perlu memasukkan username dan password yang ada pada email zimbra mereka. 
Untuk pengembangan lebih lanjut, SSO bisa diterapkan untuk mengakses beberapa aplikasi hanya dengan menggunakan username dan password yang telah dibuat pada email zimbra sebelumnya.

\section{KESIMPULAN}

Berdasarkan analisis dan pembahasan dapat disimpulkan:

a. Topologi baru yang harus diterapkan agar sesuai dengan sistem yang akan diterapkan adalah topologi yang ditambahkan dengan perangkat mikrotik router board dan juga menggunakan alamat IP yang berbeda untuk client dan servernya.

b. Load balancing dengan metode Fail Over dan PCC yang diterapkan mampu menghindari permasalahan overload pada salah satu jalur koneksi, dapat memperkecil waktu tanggap (uptime dan downtime), dan dapat mengoptimalkan trafik yang ada dalam sistem jaringan B2TE.

c. Sistem load balancing dengan metode PCC yang diterapkan dapat menangani permasalahan terjadinya overload pada salah satu jalur internet. Dengan perbandingan PCC yang telah dibuat pemeratan beban trafik jadi lebih merata.

d. Metode HTB mampu melakukan limitasi bandwidth terhadap user sesuai dengan fungsinya yaitu sebagai bandwidth limitter.

e. Metode Per Connection Quene (PCQ) mampu membatasi maksimal data rate untuk setiap sub quene (pcq-rate) dan jumlah paket data (pcq-limit).

f. Metode HTB dan PCQ yang digunakan mampu mengoptimalkan penggunaan bandwidth yang ada.

g. Sistem hotspot dapat mengatur hak akses dari tiap-tiap user yang ada pada sistem jaringan B2TE.

h. Penerapan Sistem Single sign on dapat meminimalisir penggunaan username dan password.

\section{Saran}

a. Agar sistem manajemen bandwidth yang telah diterapkan dapat lebih optimal sebaiknya ditambahkan rule yang dapat mengklasifikasikan penggunaan bandwidth lokal dan bandwidth internasional.

b. Supaya keamanan dalam jaringan lebih terjamin sebaiknya memberlakukan kebijakan baik dari segi akses alamat IP maupun akses port. Menentukan alamat IP dan port mana saja yang diizinkan untuk diakses ataupun tidak boleh diakses.

c. Dari sisi hak akses, diterapkan penjadwalan terhadap akses-akses tertentu. Seperti situs jejaring sosial yang hanya bias diakses pada saat jam istirahat.

d. Untuk pengembangan lebih lanjut, SSO dapat diterapkan untuk tidak hanya untuk dua akses aplikasi, tetapi dapat mengakses multi aplikasi. 
ANALISIS DAN IMPLEMENTASI MIKROTIK ROUTER BOARD...

\section{REFERENSI}

Aaslund, K., Larsen, S. 2007. OTS-Wiki: A Web Community for Fostering Evaluation and Selection of Off-The-Shelf Software Components. Department of Computer and Information Science. Norwegian University of Science and Technology (NTNU)

Arikunto, Prof. Dr. Suharsimi. 2006. Prosedur Penelitian Suatu Pendekatan Praktik Edisi Ketiga. Jakarta: Rineka Cipta

Brenton, Chris. 2001. Active Defense : A Comprehensive Guide To Network Security. Sybex.

Carter, Gerald .2003. LDAP System Administration. O'Reilly. 1005 Gravenstein Highway North Sebastopol, CA 95472, U.S.A.

C. Rigney, S. Willens, A. Rubens, W. Simpson, "Remote Authentication Dial In User Service (RADIUS)", RFC 2138, 1997, http://www.ietf.org/rfc/rfc2138.txt, (7 Agustus 2011)

Dewobroto, Pujo. 2010. Load balancing Menggunakan Metode PCC. [online]. Tersedia: http://www.mikrotik.co.id/artikel lihat.php?id=34

Goldman, James E and Philips Rawles. 2001. Applied Data Communications, A Business-Oriented Approach, Third Edition. West Sussex : John Wiley and Sons

Herlambang, M. Linto dan Catur L. Aziz. 2008. Panduan Lengkap Menguasai Router Masa Depan Menggunakan Mikrotik Router OS. Yogyakarta: ANDI

Hassel, J. 2002. RADIUS. Sebastopol. O’Reilly.

MTCNA, Tim Penyusun. Mikrotik Training Basic. 2009

Nazir, Moh. 2005. Metode Penelitian. Jakarta: Ghalia Indonesia

Riyadi, Valens. 2010. Mendalami HTB Pada QOS RouterOS Mikrotik. [online]. Tersedia: http://www.mikrotik.co.id/artikel lihat.php?id=29

Saputro, Daniel T.\& Kustanto. 2008. Membangun Server Internet Dengan Mikrotik OS. Yogyakarta: Gava Media

Setiawan, Deris. 2009. Fundamental InterNetworking Development and Design Life Cycle . [online]. Tersedia: www.deris.unsri.ac.id/materi/jarkom/Network_development_-cycle.[2011-1226]

Sopandi, Dede. 2010. Instalasi dan Konfigurasi Jaringan Komputer. Jakarta: Informatika

Stalling, William. 2003. Criptography and Network Security : Principles and Practice. Prentice-Hall. New Jersey

Subramanian, Mani. 2000. Network Management Principles and Practice. Addison. Wesley Longman Inc

Wikipedia. 2011. Single sign-on - Wikipedia, the free encyclopedia. Online: http://en.wikipedia.org/wiki/Single_sign-on. accessed: 2011-12-27. 